Ankara Üniversitesi Dil ve Tarih-Coğrafya Fakültesi Türkoloji Dergisi

19, 1 (2012) 23-32

\title{
Şiir Dilinde Sözcük Seçimi : Âzerî’nin Husrev ü Şîrîn’inde Gömüt Örneği
}

\section{Ülkü ÇETINKAYA*}

Özet: Edebî metinlerin anlaşılması, yorumlanması ve dolayısıyla edebî değerlerinin belirlenmesinde öncelikle o metnin türüne özgü bir dil çözümlemesinin yapılması en temel şarttır. Edebiyatın en önemli türü olan şiir, anlam ve anlatımıyla bir bütündür. Şairler şiirin özünün söze dönüş̧ürülmesi sırasında, dilin daha önce kullanılmış ya da kullanılmamış olan bütün anlatım imkânlarından yararlanarak özel bir dil yaratırlar. Bu özel dilin oluşumunda, sözcüklerin seçimi ve anlam çerçeveleri gözetilerek dizelere yerleştirilmesi son derece önemlidir.

Bu çalışmada, şiir dilinde ve şairin üslubunda en önemli hususlardan biri olan sözcük seçimi ve birleştirilmesi bağlamında, XVI. yüzyıl Divan şairlerinden Bursalı Âzerî İbrahim Çelebi (öl.1585)'nin Husrev ü Şirin mesnevisinde geçen "gömüt" sözcüğ̈̈ değerlendirilmiştir.

Anahtar Sözcükler: Âzerî İbrahim Çelebi, şiir dili, gömüt, neolojizm, anlık oluşum, sözcük seçimi

Word Choice in Poetic Language: Example of 'Gömüt' in Azerî's Husraw and Shireen

Abstract: The main prerequisite to comprehend and interpret literary works and thus to determine their literary value is to conduct a language analysis specific to the text type. Being the most important type of the literature, the poetry is a whole with its meaning and expression. While transforming the core of the poem into words, poets create a specific

\footnotetext{
* Yrd.Doç.Dr., Ankara Üniversitesi, Dil ve Tarih-Coğrafya Fakültesi, Türk Dili ve Edebiyatı Bölümü.

e-posta: cetinkayaulku@gmail.com
} 
language by using each and every, used or unused, expression means of the language. In the formation of this specific language, it is significantly important to choose words and place them into verses according to the meaning framework.

This study assesses the word "gömüt (grave)" in the Husraw and Shireen masnavi of Azeri İbrahim Çelebi from Bursa (?- 1585) who was a $X V I$. Divan poet, within the scope of choice and combination of word which is one of the most important issues in poetic language and poetry style.

Key Words: Âzerî İbrahim Çelebi, poetic language, "gömüt", neologism, nonce formation, word choice

Edebî metinleri anlama ve yorumlama yolunun öncelikle o metinlerde kullanılan dili çözümlemek olduğu, bilinen bir gerçektir. Dolayısıyla bir metnin dili, o metnin edebî değerinin belirlenmesinde en temel ölçüttür.

Yüzyıllar boyu edebiyatın en önemli türü sayılan şiir, "gerek içerik ve öz, gerekse söze dönüş̧ürme ve sunuluş açısından özgün, etkilemeye ve duygulandırmaya yönelik, yaratı niteliği taşıyan bir söz sanatı ürünüdür." (Günay 2001: 212). Şiirin içeriğinin şair tarafından sunuluş biçiminin özgünlüğü, hem eserin başarısı ve değeri, hem de onu yaratan şairin üslubu hakkında verilecek hükümler açısından son derece önemlidir. Kısacası şiirde esas olan, şairlerin neyi söyledikleri değil, nasıl söyledikleridir.

Sözcükler ve onların bir araya getiriliş esaslarının temel iki nokta kabul edildiği şiirde, günlük dilden (günlük konuşma ve yazı dilinden) ve diğer edebî türlerde kullanılan dilden ayrı, kendine özgü bir dil (şiir dili) vardır. $\mathrm{Bu}$ dil, şairlerin olağan dilde kullanılan sözcükleri özenli bir seçme ve yepyeni bağlantılarla bir araya getirmedeki ustalıklarıyla, dilin anlatım gücünü üst seviyeye taşımaları sonucu oluşmuş özel bir dildir.

Biçim, ölçü, kafiye gibi şiirin dış yapısıyla ilgili zorlamaların yanı sıra, okuyucu üzerindeki etki gücü ve hatırda kalabilmesi gibi nedenler dolayısıyla az sözle çok şey anlatmak, şiir dilinin en önemli özelliklerindendir. Şairlerin bunu, sözcük seçimine özen göstererek, gereksiz sözcüklerden kaçınarak ve seçtikleri sözcüklerin anlam ve çağrışım zenginliğinden yararlanarak sağladıkları görülür. Sözcük seçiminde, sözcüklerin eş adlılık, çok anlamlılık, yan anlam, zıtlık vb. ilişkilerini gözeterek anlam yoğunluğu yaratmayı amaçlayan şair, zaman zaman seyrek kullanılan sözcükleri kullanabileceği gibi, çok az da olsa yeni sözcükler türetme yoluna da gidebilir.

Türk şiirinin tarihî seyri içinde, teorik ve estetik esasları belirli bir gelenek çizgisinde altı yüz yıl varlık göstermiş Divan şiirinde de konudan 
çok üsluba (söyleyişe, dili kullanımda özgünlüğe) önem verilmiştir. Öyle ki aynı konuların yüzyıllarca işlenmiş olduğu bu şiir anlayışında bireysellik, şairlerin dilin tüm imkânlarından faydalanarak farklı ve üstün bir söyleyiş gücü sergileme çabalarında kendini göstermiştir. Dolayısıyla, Divan şiirinde de sözcük seçimi büyük önem taşımıştır. Bu konuda Aksan şunları söylemiştir:

"Kullanılan sözcükler ölçü (aruz ölçüsü) içindeki yerleri, ses değerleri, özellikle de anlam açısından nitelikleri göz önünde tutularak seçilmekteydi. Bir beyitte kullanılan bir sözcük, çeşitli söz sanatlarını gerçekleştirebilmek ve başkalarıly ilişkiye sokulmak üzere belirlenmekte, kimi zaman birden çok anlamın su üstüne çıkması amactyla şiirde yer almakta ve beyit çeşitli anımsatmalar, çağrışımlarla ve ses açısından sağladı̆̆ olanaklarla etkili olmaya yönelmektedir." (2006a: 68-69).

Divan şairleri kendi şiirlerinde de şiirin nasıl olması gerektiğine ilişkin görüşlerini sıkça dile getirmişler, az sözle çok şey anlatmanın önemi hemen hemen her şair tarafindan vurgulanan bir husus olmuştur. Nitekim, edebî kişiliğinin en öne çıkan yanı söyleyiş gücü olan şair Nedim (öl. 1730) az, öz, ölçülü ve anlamca zengin söylenen sözün mücevher gibi değerli olduğunu veciz biçimde şöyle dile getirmiştir:

"Sözi az söyle ağır söyle Nedimā ki suhan

Zer gibi sayll gevher gibi sencīde gerek” (Boztepe1338-40: 152)

Divan şairlerinin sözcük seçimindeki özen ve hassasiyetlerine, bir örnek teşkil etmesi bakımından bu çalışmada, XVI. yüzyıl Divan şairlerinden, Âzerî mahlasıyla tanınan Bursalı İbrahim Çelebi (öl. 1585)'nin Husrev ü Şirin mesnevisinde geçen gömüt sözcügüü üzerinde durulacaktır ${ }^{1}$.

Husrev $\ddot{u}$ Şirin'in transkripsiyonlu metnini hazırlarken, metinde Arap harfleriyle (كموت) biçiminde yazılmış olan bu sözcüğün ilk bakışta ne olduğu anlaşılamadığından çeşitli okuma ihtimalleri değerlendirildi. Ancak sözlüklerde bu imlayla yazılmış bir sözcüğe rastlanamadı. Beytin bağlamıyla

${ }^{1}$ Âzerî İbrahim Çelebi (öl.1585)'nin kaynaklarda varlığından söz edilmeyen, ancak son zamanlarda tespit edilen tek yazma nüshası Macar Bilimler Akademisi Kütüphanesi Török O.427 numarada kayıtlı (Parlatır vd. 2007: 112-13) Husrev $\ddot{u}$ Şirin mesnevisi hakkında bilgi için bk. (Çetinkaya 2008: 84-102). 
ilişkisi dikkate alındığında, bu sözcügün gömüt okunmasının doğru olacağı sonucuna varıldı.

Bugüne kadar okunan tarihî metinlerde ve bu yazıyı hazırlama aşamasında taranan çok sayıda metinde ${ }^{2}$ de rastlanamayan bu sözcügüun, XVI. yüzyılda yazılmış bir metinde yer almış olması ve şairin bu sözcügüü kullanımındaki tasarrufu dikkat çekicidir. Bu nedenle, çalışmanın bundan sonraki bölümlerinde, adı geçen sözcüğün güncel sözlüklerdeki anlamı, metindeki anlamı ve diğer sözcüklerle ilişkisi, şairin bu sözcüğü seçmesinin nedenleri, sözcügün metnin yazıldığı dönemde veya önceki dönemlerde de kullanılıp kullanılmadığı veya şair tarafından türetilmiş bir sözcük olup olmadığı ile ilgili hususlar değerlendirilecektir.

Yukarıda belirtildiği üzere, Türkçenin tarihî sözlüklerinde bulunmadığı tespit edilen gömütün, kimi güncel ve genel Türkçe sözlüklerde yeni bir sözcük (neolojizm) olduğu belirtilmiştir ${ }^{3}$. Madde başı olarak yer aldığ sözlüklerde bu sözcügün anlamı "mezar, metfen, kabir, makber, sin, ölü gömülen yer" (Türkçe Sözlük 2005: 776; Ayverdi 2011: 429; Tietze 2009: 172; Püsküllüoğlu 2002: 244; Çağbayır 2007: 1747; $\operatorname{Timurtaş}^{4}$ 1979: 99) olarak geçmektedir.

Derleme Sözlüğ̈̈’nde gömüt sözcüğü yoktur. Ancak ayn1 kökten türemiş gömük ile gömüt sözcügüne isimden isim yapma eki olan -lük eki getirilerek türetilmiş gömütlük yer almaktadır. Gömütlük burada sazlık, bataklık anlamındaki gömük(I) ile eşanlamlı gösterilmiştir (Derleme Sözlüğü 1993: 2150-51). Buna karş1lı gömütlükün anlamı diğer bazı sözlüklerde “mezarlık, kabristan, ölülerin gömüldü̆̈̈̈, yani gömütlerin bulunduğu alan” (Türkçe Sözlük 2005: 776 ; Tietze 2009:172; Timurtaş 1979: 99; Püsküllüoğlu 2002: 244; Çağbayır 2007: 1747) olarak geçmektedir. Fakat Derleme Sözlüğünde madde baş1 olarak gömüte rastlanmazken gömütlükün yer almış olması gömütün de tarihî süreçte dilde var olan bir sözcük

${ }^{2} \mathrm{Bu}$ çalışma sırasında XIV. ve XIX. yüzyıllar arasında yazılmış, yüze yakın divan ve mesnevî metni taranmıştır. $\mathrm{Bu}$ eserler makale içinde tek tek anıldığında "kaynakça"nın geniş bir hacme erişeceği düşüncesiyle belirtilmemiştir.

3 "Gömüt"ün yeni bir sözcük olduğu belirtilen sözlüklerde yer alan bilgiler şöyledir: "gömüt (Néologisme) 'mezar' < göm-+ ??, tabut gibi mi? Senin olsun o tarla! Eş, kaz, gömüt olsun, içine gir! (Ü Kaftancioğlu 1972, s.71) Ben ölende, bana gömüt yapmasinlar, gömmesinler, varsin bir dikili taşım olmasın. İstemem. (a.e. s.72)" (Tietze 2009:172); "gömüt i. (<göm-ü-t) yeni. Mezar, kabir, makber." (Ayverdi 2010: 429). "gömüt, [göm-üt] is. Ölünün gömüldü̆̈̈̈ yer; mezar (1944)." (Çağbayır 2007: 1747).

${ }^{4}$ Timurtaş'ın bu sözlükteki sözcüklerin dizilişiyle ilgili açıklamalarına göre (1979: 69) gömüt ve gömütlük yanlış ve uydurma olan sözcüklerdendir. 
olduğunu düşündürmektedir. ${ }^{5}$ Öte yandan bu sözlükte sazlık, bataklık anlamında gömütlük, gömük ve gömüklükün yanı sıra, muhtemelen gömütün bozulmuş biçimi olan günüt sözcüğü de yer almaktadır. Türkçede bataklık anlamındaki sözcüklerin "gömük/gömüklük, sazak/sazaklık, şamak/şamaklık, valta/valtalık (Eren 2010: 163)" örneklerinde olduğu gibi, isim yapma eki $l ı k$, -lik, -luk, -lük getirilerek oluşturulmuş biçimlerle ikili bir yapı içinde oldukları görülmektedir. Bu durum, gömüt/gömütlük veya günüt/günütlük sözcüklerinin de var olabileceğini düşündürmektedir. Fakat bu sözlükte sazlık ve bataklık anlamında gömüt ve günütlük sözcükleri yoktur. Diğer taraftan günütün, Hasan Eren'in farklı örneklerde işaret ettiği (Eren 2010) gibi, Derleme Sözlüğü çalışmaları sırasında derleyenler tarafından yanlış yazılmış bir sözcük olma ihtimalini de göz önünde bulundurmak gerekir.

Gömüt sözcüğü Âzerî'nin Husrev ü Şirin mesnevisinde, Sasanî hükümdarlarından Husrev-i Perviz ile onun siyasi rakiplerinden Behrâm-1 Çûbîn arasındaki taht mücadelesi yüzünden yaşanan savaşın anlatıldığı Şıfat1 suḅ̣ u ceng-i Husrev bā-Behrām-1 Çübinn (Behrâm-1 Çûbîn ile Husrev'in savaşı ve sabah tasviri) başlıklı bölümde (Âzerî İbrahim Çelebi: 37b-38b) geçmektedir. Mesnevinin 1037. ve 1069. beyitleri arasında yer alan bu bölümde, bir sabah Behrâm ile Husrev'in askerlerinin karşı karşıya gelişi, amansız bir savaşın sonunda Behrâm'ın ordusunun mağlup olup Husrev'in tahta geçişi anlatılmaktadır. Aşağıda, konuya ilişkin değerlendirmelerin daha anlaşılır olmasını sağlamak düşüncesiyle, gömüt sözcügünün de yer aldığı, savaş sabahının tasvir edildiği 1037. ve 1041. beyitlere (Âzerî İbrahim Çelebi: $37 b)$ yer verilmiştir:

Bir șubḥ ki çekdi mihr rāyet

Şemşiri ref $f^{\prime}-i$ cevr-i zulmet

Mag̉lūb olup 'asākir-i şām

\footnotetext{
${ }^{5}$ Doğan Aksan, Köktürk metinlerinde rastlanan buna benzer durumlara ilişkin olarak verdiği bilgiler arasında şunlara değinmektedir: "Bilindiği gibi türemiş bir sözcüğün, örneğin tutumluluk, soysuzlaşma, karş̧laş̧trma gibi sözcüklerin dilde var olabilmesi için bunların kökü olan tut-, soy, karşı gibi öğelerin de bulunmasl gerekir. Eğer kök olan bu öğeler geçmezken türevleri dilde kullanillyorsa bu, köklerin de o dönemde bulunduğu, ancak konuların sinırlılığ nedeniyle metinlerde yer almadiğ l anlamina gelir. İşte, Köktürk metinlerinde bu türden türevlerle (ileri öğelerle) karşılaşmaktayız ki bunlar hem dönemin söz varlı̆̆ının bilinenden daha geniş olduğunu, hem de bu türetmelerin dildeki gelişmeyle zaman içinde gerçekleştiğini göstermektedir." (2006b:88). Buna göre "gömütlük" gömütten türemiş bir "ileri öğe"dir.
} 
Gizlendi gömüte girdi Behrām

Bārū-yı sipihri aldı hưrşìd

Meh ḳald nuhūset üzre nevmìd

Tïg aldı eline şāh-1 ḩāver

Zerrātdan itdi cem'-i leşker

Tağıldı mevākib-i kevākib

Yüz tutdı gürīze necm-i șạkıb

$\mathrm{Bu}$ beyitlerde, sabahleyin güneşin doğuşuyla gecenin son buluşu şöyle tasvir edilmiştir: Bir sabah, kılıcı karanlığın zulmüne son veren güneş bayrak çekmiş, gecenin askerleri (yıldızlar) mağlup olmuş, Behrâm (Mirrih, Mars) gömüte girip gizlenmiştir. Güneş, gökyüzünün kalesini ele geçirince ay uğursuzluk içinde, ümitsiz bir şekilde kalakalmıştır. Doğunun hükümdarı (güneş) eline kılıcını alıp, zerrelerden (güneş 1şı̆̆ı ile kendini gösteren toz zerreciklerinden) ordu kurmuş, bunu gören yıldız alayları dağılmış, en parlak yıldız kaçmaya yüz tutmuştur. Mesnevide bu beyitlerden hemen sonra hikâyenin kahramanlarından Husrev ile Behrâm-1 Çûbîn'in savaşı anlatılmaya başlanmıştır. Şair asıl konuya geçmeden önce, olayın gerçekleştiği sabah vaktini de konuya uygun olarak, gece vakti gökyüzündeki gök cisimleri ile güneşin savaş sahnesi şeklinde tasvir etmiştir.

Çalışmaya konu olan gömüt sözcüğünün geçtiği beyitte Behrâm (Far.) sözcügü ile kastedilen, eski astronomide yedi gezegenden (heft-ahter) biri olan ve İranlı gökbilimcilerin Behrâm dediği gezegendir. Behrâm Arapçada Mirrîh (Merih), Yunancada Mars olarak bilinir (Yıldırım 2006: 146). Bu gezegene, edebiyatta kahramanlık sembolü olan Behrâm'dan kinaye olarak Behrâm-l felek de denmiştir (Onay 1993: 293).

Gezegen anlamındaki Behrâm dışında, İran ve Divan şiirinde adı geçen bir başka Behrâm daha vardır. Bu kiși İran mitolojisinde Sasanî hükümdarlarından V. Behrâm olarak da bilinen Behrâm-ı Gûr bin Yezdicerd'dir. Sürekli olarak yabaneşeği avına çıktığ 1 için adı yabaneşeği anlamındaki gûr sözcügüyle birlikte Behrâm-l Gûr olarak bilinir. Yabaneşeği avı sırasında bir çukura düşerek kaybolmuştur. (Yı1dırım 2006: 148). A. Talat Onay'ın verdiği bilgiye göre, bir gün önünden kaçan avın ardına düşen Behrâm, hayvan bir mağaraya girince ardından girmiş ve bir daha çıkmamıştır. (1993: 10). Behrâm'ın lakab1 olan gûr sözcüğü ise Farsça'da “Gūr (1): Cāȳi ki mürderā der-ān defn konend [Ölülerin gömüldügüu yer], kabr [kabir, mezar]. Gūr (2): 1. Deşt, sahra [ova, kır], 2. 
Cāy-1 bī-āb u 'alef ki püşte vü şikestegī bisyār dāşste başed [Otsuz, susuz çorak yer, bozkır] 3. Gūr-ḩar [yaban eşeği]." (Mu'în 1364: 3433-34) anlamlarına gelmektedir.

Buraya kadar Behrâm ve gûr sözcüklerinin anlamı üzerinde uzun uzun durulmasının sebebi, bu iki sözcügün bahse konu olan gömüt sözcüğü ile ilgisi dolayısıyladır. Şair beyitte Behrâm sözcüğünü gezegen adı olarak kullanmışsa da Behrâm-l Gûr'u da çağrıştırarak tevriye yapmıştır. Çünkü beyit içinde gömüt sözcügünün, içine girilip gizlenilen bir yer anlamına geldiği açıtır. Şairler şiirlerinde Behrâm'ın lakabı olan gûr sözcügünü, hem Behrâm'ın yabaneşeği avına düşkünlüğü dolayısıyla yabaneşeği anlamında hem de av sırasında bir çukura düşerek kayboluşu dolayısıyla çukur, mezar anlamında kullanmışlardır. Âzerî de söz konusu beyitte, Behrâm (Mirrîh) sözcügüyle Behrâm-l Gûr'u da çağnıştırırken; gûrun çukur, mezar anlamının karş1lı̆̆1 olarak Türkçe gömüt sözcügünü kullanmıştır. Ancak gömütün metinde doğrudan mezar anlamında değil, çukur, siper anlamında kullanıldığı anlaşılmaktadır. Çünkü gömüt sözcüğünün geçtiği beyit ile ondan önceki ve sonraki beyitler birlikte değerlendirildiğinde; sabah vakti, kılıcı karanlığın zulmüne son veren güneşin bayrak çektiği, gecenin askerlerinin (yıldızlar) mağlup olup Behrâm (Mirrîh, Mars)'ın gömüte girerek gizlendiğinden ve güneşin, gökyüzünün kalesini ele geçirince ayın uğursuzluk içinde, ümitsiz bir ş̧ekilde kalakaldığından söz edildiği görülmektedir. Savaş sırasında Behrâm'ın öldüğünden değil, gizlendiğinden ve güneşin gökyüzünün kalesini ele geçirdiğinden söz edildiğine göre, gömüt burada "Muharebede askerin kurşun ve gülleden korunması için toprak kazılarak açılan ve ön tarafina çıkan topraklar yığılmak suretiyle vücuda getirilen korunma yeri (Pakalın 1993: 235)" demek olan siper anlamında kullanılmıştır. Şu ana kadar başka bir tarihî metinde kullanım örneğine rastlanılamayan bu sözcügün buradaki siper anlamının yanı sıra, başka bir şair veya yazar tarafından mezar anlamında kullanılmış olabileceğini de göz ard1 etmemek gerekir. Gömütün yeni bir sözcük olduğu belirtilen güncel sözlüklerde mezar anlamına geldiği yukarıda belirtilmişti.

Peki, şair metnin veznine de uyduğu hâlde niçin siper (Far.) veya mezâr (Ar.) sözcüklerinden birini değil de gömütü tercih etmiştir? Her üç sözcük de özünde toprak kazılarak oluşturulmuş çukur anlamını barındırmakla birlikte, beyitte özne durumundaki Behrâm'ın öldügü değil bizzat gömüte girip gizlendiği söylenmektedir. Mezar söz konusu olduğunda bir insanın mezara girip gizlenmesinden değil, gömülmesinden söz edilebilir. Siper sözcüğüne gelince, gizlenme yeri anlamı itibariyle beyte çok uygun görünmesine rağmen Behrâm (Mirrîh) ile çağrıştırılan Behrâm-ı Gûr'daki gûrun mezar anlamının çağrışımı ortadan kalkacağı için tercih edilmemiş olabileceği 
söylenebilir. Öte yandan, söz konusu beytin ikinci mısrasında gizlendi gömüte girdi sözcüklerindeki $g$ sesi ile yaratılan aliterasyon da şairin gömütü tercihinde rol oynayan bir unsur olarak değerlendirilmelidir.

Derleme Sözlüğ̈̈'ndeki gömütlük sözcügünün, gömütün de Türkçenin tarihî dönemlerinde dilde var olan bir sözcük olma ihtimalini düşündürdüğüne yukarıda değinilmişti. Ancak bu ihtimal göz önünde bulundurulsa bile, pek çok eser taranarak oluşturulan tarihî sözlüklere girmemiş olması, en azından gömütün yaygın biçimde kullanılan bir sözcük olmadığını ortaya koymaktadır. Bütün bunların yanı sıra, bir başka ihtimal de adı geçen sözcüğün, Âzerî tarafindan türetilmiş bir anlık oluşum (nonce formation) olabileceğidir. Çünkü bir biçimbilim (morphology) terimi olan anlık oluşum (nonce formation): "Belirli bir bağlamda bireysel olarak kullanılan ilk türetim; türetilen sözcük, kullanıldı̆̆ dilin sözlüğ̈̈ne girmiş değildir." (İmer vd. 2011: 30). şeklinde tanımlanmaktadır.

"Anlık oluşumlar dillerdeki yeni sözcüklerin asıl kaynağıdır. Bu oluşumlar başka ortamlarda tekrarlanır ve belirli bir siklı̆̆a ulaşırsa, yalnızca anlık oluşumun sahibi tarafindan değil, başkalart tarafindan da kullanılmaya başlarsa, bu oluşum artık yaygınlaşmış ve tutunmaya başlamış demektir. Yeni bir sözcügün dilde belirli bir sözlüksel içerikle belirli bir çapta yaygınlaşması, tutunması sözlükselleşme (lexicalisation) olarak adlandırllır. Sözlükselleşmiş sözcükler artık o dilin söz varlı̆̆ına ait olmuş sözcüklerdir." (Uzun 2006: 89).

Eski Türkçeden beri fiilden isim türeten $-t$ eki, Eski Türkçede "kurut, ölüt, ögit, vb. (Erdal 1991: 308-316)"; Eski Anadolu Türkçesinde "içit, binit, kurut, yüklet, geçüt vb. (Ergin 1993: 184)" ve günümüz Türkçesinde yanıt, ögüt, umut, yoğurt vb. sözcüklerde görülmektedir. Gömüt de göm- fiiline aynı ek getirilerek türetilmiş bir sözcüktür.

\section{Sonuç}

Âzerî İbrahim Çelebi (öl. 1585)'nin Husrev ü Şirin mesnevisinde tespit edilen gömüt sözcügü̆, Türkçenin tarihî sözlüklerinde yer almamıştır. Bazı güncel ve genel Türkçe sözlüklerde ise tanıklarla desteklenerek yeni bir sözcük (neolojizm) olduğu belirtilmiştir. Şimdiye kadar yaptığımız araştırmalarda söz konusu mesnevi dışında başka bir tarihî metinde rastlanamayan gömütün, bu çalışma sonunda, yeni bir sözcük olmadığı, XVI. yüzyılda kullanıldığı ortaya çıkmıştır. 
Gömütün Türkçenin tarihî dönemlerinde dilde var olan bir sözcük olma ihtimalini göz ardı etmemekle birlikte, pek çok eser taranarak oluşturulan tarihî sözlüklere girmemiş olması en azından yaygın biçimde kullanılmadığını (sözlükselleşmediğini) göstermektedir. Bundan dolayı, adı geçen sözcügün, Âzerî tarafindan türetilmiş bir anlık oluşum (nonce formation) olabileceği bir başka ihtimal olarak değerlendirilmiştir. Güncel sözlüklerde yeni bir sözcük olduğu belirtilen gömüt, anlık bir oluşum kabul edilse bile, tarihî süreçte yaygınlaşamadan kullanımdan düşmüş, daha sonra Türkiye Türkçesinde aynı türetme mantığı ile söz varlığına kazandırılmış bir sözcük de olabilir.

Gömütün Azerî tarafından türetilmiş bir sözcük olduğu varsayılırsa, şairlerin sadece dildeki mevcut sözcükleri kullanarak yaratıcılıklarını sergilemedikleri, farklı bir söyleyiş yakalamak için sözcük türetme yoluna da gidebildikleri sonucuna varılır.

Güncel sözlüklerde mezar, ölü gömülen yer anlamına geldiği belirtilen gömütün Âzerî tarafından, konuyla ve beyitte geçen diğer sözcüklerle ilişkilendirilerek çukur, siper anlamında kullanıldığı anlaşılmıştır. Dolayısıyla şiir dilinde her sözcüğün, şiirin diğer sözcüklerine anlam kazandıracak şekilde yerini bulduğu anlayışına uygun bir dil kullanımı sergilenmiştir. İster tarihî süreçte var olan bir sözcük, ister anlık oluşum kabul edilsin, söz konusu şiirde gömüt, Âzerî’nin Behrâm sözcüğünün çağrışım zenginliğinden faydalanarak yarattığı anlam çerçevesi ${ }^{6}$ içinde anlam kazanmıştır. Şairin bu tasarrufları, sözcük seçiminin şiir dilinde ve şairin üslubunda ne kadar önemli olduğunu bir kez daha ortaya koymuştur. Dolayısıyla şiir dili ve özellikle üslup çalışmalarında okuyucu/araştırmacıların da bu dikkat ve bakış açısı ile yapacakları değerlendirmeler, özellikle şairlerin üslupları hakkında nesnellikten uzak, yüzeysel hükümlerin verilmesinin önüne geçecektir. $\mathrm{Bu}$ durum, edebî metinlerin işlevsel sözlük ve bağlamlı dizin (concordance)lerinin hazırlanmasının başta üslup çalışmaları olmak üzere, Türkçenin söz varlığı, sözlük çalışmaları ve dil incelemeleri açısından önemini ve gerekliliğini de gözler önüne sermektedir.

\footnotetext{
6 “Anlam çerçevesi terimi, göstergelerin dil düzeni içinde anlam açısından taşıdı ğ bütün değerleri, temel anlamlarıyla birlikte yan anlamlarını, dinleyen/okuyanda çağrıştırdığı başka kavramların tümünü içine almaktadır.” (Aksan 2006:76).
} 


\section{KAYNAKLAR}

AKSAN, Doğan (2006a). Şiir Dili ve Türk Şiir Dili, Ankara: Engin Yayınevi.

AKSAN, Doğan (2006b). Türkçenin Sözvarlığı, Ankara: Engin Yayınevi.

AYVERDİ, İlhan (2011). Misalli Büyük Türkçe Sözlük (Kubbealtı Lugatı), İstanbul: Kubbealtı Yayınları.

Âzerî İbrahim Çelebi, Husrev ü Şîrîn, Macar Bilimler Akademisi Kütüphanesi Török O. 427.

BOZTEPE, Halil Nihat (1338-40). Nedim Divanı, İstanbul: İkdam Matbaası.

ÇAĞBAYIR, Yaşar (2007). Orhun Yazıtlarından Günümüze Türkiye Türkçesinin Söz Varlığı (Ötüken Türkçe Sözlük), 2, İstanbul: Ötüken Neşriyat.

ÇETINNKAYA, Ülkü (2008). “A Husrev ü Şirin by Azeri”, International Journal of Central Asian Studies, 12, Seoul: 84-102.

Derleme Sözlüğü (1993). XII, Ankara: TDK Yayınları.

ERDAL, Marcel (1991). Old Turkic Word Formation A Functional Approach to the Lexicon, 2, Wiesbaden.

EREN, Hasan (2010). Sırça Köşkte, Ankara: TDK. Yayınları.

ERGIN, Muharrem (1993). Türk Dil Bilgisi, İstanbul: Bayrak Yayınları.

GÜNAY, Doğan (2001). Metin Bilgisi, İstanbul: Multilingual Yayınları.

İMER, Kâmile, Kocaman, Ahmet ve Özsoy A.Sumru (2011). Dilbilim Sözlüğü, İstanbul: Boğaziçi Üniversitesi Yayınları.

MU'ÎN, Muhammed (1364). Ferheng-i Fârsî, 6, Tehran.

ONAY, Ahmet Talat (1993). Eski Türk Edebiyatında Mazmunlar. haz. Cemâl Kurnaz, Ankara: Türkiye Diyanet Vakfı Yayınları.

PAKALIN, Mehmet Zeki (1993). Osmanlı Tarih Deyimleri ve Terimleri Sözlüğü, 3, İstanbul: MEB. Yayınları.

PARLATIR, İsmail-Hazai, György (2007). Macar Bilimler Akademisi Kütüphanesindeki Türkçe El Yazmaları Kataloğu, Ankara: Türkiye Bilimler Akademisi Yayınları.

PÜSKÜLLÜOĞLU, Ali (2002). Öz Türkçe Sözlük, Ankara: Arkadaş Yayınları.

TİETZE, Andreas (2009). Tarihi ve Etimolojik Türkiye Türkçesi Lugati (Sprachgeschichtliches und Etymologisches Wörterbuch des Türke1-Türkıschen), 2, Wien.

TİMURTAŞ, Faruk Kadri (1979). Uydurma Olan ve Olmayan Yeni Kelimeler Sözlüğü, İstanbul: Umur Yayıncılık.

Türkçe Sözlük (2005). Ankara: TDK Yayınları.

UZUN, Nadir Engin (2006). Biçimbilim, İstanbul: Papatya Yayınları.

YILDIRIM, Nimet (2006). Fars Mitolojisi Sözlüğü, İstanbul: Kabalcı Yayınları. 